\title{
USULAN PERBAIKAN OPERATION POINT SHEET PADA MESIN FEEDER AIDA 1100 PT. XXX DENGAN MENGGUNAKAN METODE SMED
}

\author{
Ary Arvianto, Rheza Arista \\ Program Studi Teknik Industri \\ Universitas Diponegoro Semarang \\ Jl. Prof Sudarto, SH., Semarang \\ aryarvi@yahoo.com
}

\begin{abstract}
Abstrak
Single Minute Exchange of Die (SMED) merupakan salah satu alat lean yang penting untuk mengurangi waste dan meningkatkan fleksibilitas dalam proses manufaktur yang memungkinkan dalam pengurangan ukuran lot dan perbaikan aliran manufaktur. SMED mengurangi waktu non-produktif dengan mempersatukan dan standardisasi operasi dalam pergantian alat, dengan menggunakan teknik sederhana dan aplikasi yang mudah. Namun proses tersebut tidak dapat memberikan hasil yang spesifik dalam pelaksanaannya, dimana masih dapat dilakukan suatu perbaikan. Untuk mengatasi hal ini, data statistik dan alat-alat teknik industri dapat diintegrasikan dalam pendekatan SMED untuk meningkatkan hasil penerapan SMED. Penerapan pendekatan SMED yang diusulkan diuji untuk mesin feeder didalam industri otomotif PT. XXX. Implementasi ini memungkinkan adanya pengurangan waktu setup, melalui reorganisasi sumber daya internal perusahaan tanpa membutuhkan investasi yang signifikan.
\end{abstract}

Kata kunci: Lean manufacturing systems, Single Minute Exchange of Die, Quick ChangeOver.

\begin{abstract}
Single Minute Exchange of Die (SMED) is one of the essential lean tools to reduce waste and increase flexibility in manufacturing processes that enable the reduction of lot size and improving manufacturing flow. SMED reduces non-productive time by streamlining and standardizing operations in the turn of the tool, using simple techniques and easy application. But the process can not provide a specific result in the implementation, which can still be an improvement. To overcome this, statistical data and tools can be integrated in industrial engineering approaches to improve outcomes SMED SMED implementation. The proposed application of SMED approach was tested for the automotive industry in the feeder machine PT. XXX. This implementation allows for the reduction of setup time, through the reorganization of the company's internal resources without requiring significant investment.
\end{abstract}

Keywords: Lean manufacturing systems, Single Minute Exchange of Die, quick changeover.

\section{PENDAHULUAN}

Sekarang ini Industri Otomotif
sedang berkembang pesat seiiring meningkatnya permintaan konsumen. Industri perakitan motor seperti PT. XXX saat ini sangat dituntut untuk dapat memenuhi permintaan pasar yang cenderung fluktuatif dengan spesifikasi produk yang variatif pula. Konsumen cenderung kritis dalam memilih barang yang akan dibelinya yang sesuai dengan ukuran, bentuk atau warna yang diinginkan. Perusahaan manufaktur dituntut untuk selalu dapat membuat variasi atas produk yang dihasilkannya agar dapat bersaing.

Peningkatan variasi produk ini akan berimbas pada berubahnya spesifikasi mesin produksi yang digunakan. Proses set up mesin akan semakin sering terjadi apabila masalah peningkatan variasi produk sering muncul. Perubahan warna, ukuran atau bentuk produk yang dihasilkan akan menambah kesulitan dalam proses produksi dan akan semakin sering dilakukan penggantian part-part mesin tertentu untuk memenuhi permintaan produk tersebut. Waktu produksi akan bertambah dari waktu normalnya dikarenakan hal ini. Efektivitas proses produksi ini pun pada akhirnya akan menjadi suatu hal yang sulit dicapai, masalah tersebut tentunya dipengaruhi oleh semakin tinggi dan seringnya melakukan set up mesin tadi. Titik fokus setiap perusahaan adalah 
bagaimana Mereduksi waktu yang dibutuhkan untuk melakukan set up mesin.

Dengan kondisi mesin sekarang, waktu setup yang dibutuhkan mencapai 30 menit. Ini tidak mendukung dengan adanya permasalahan meningkatnya jumlah demand konsumen, karena lamanya waktu setup sama dengan banyaknya part komponen yang tidak diproduksi. Target dalam penelitian ini adalah menurunkan waktu setup tersebut hingga 50\% agar part komponen yang tidak diproduksi dapat direduksi, sehingga dapat meningkatkan kapasitas produksi mesin.

Metode SMED (Single Minute

of Exchange Die) sebagai suatu pendekatan dianggap sebagai salah satu solusi tepat yang digunakan untuk mereduksi waktu set up mesin. Penerapan metode SMED ini telah terbukti dapat menurunkan waktu set-up. SMED juga mampu mengurangi man power, mengefektifkan waktu produksi, menurunkan ongkos produksi dan mengeliminir terjadinya kesalahan dalam melakukan set up mesin.

\section{METODOLOGI PENELITIAN SMED}

Single-Minute Exchange of Die atau lebih dikenal dengan istilah SMED saja, bermula dari sebuah problem bahwa semua aktivitas produksi yang terdiri dari proses dan operasi memerlukan set up untuk setiap mesinya baik set-up untuk running yang pertama kali atau set-up untuk changeover. Sebelum munculnya SMED, set up time sangat panjang sehingga sangat tidak ekonomis untuk sebuah perusahaan sebab dengan set-up yang lama maka akan timbul bottleneck yang akan mengakibatkan production loses. Konsep SMED muncul pada periode tahun 1950-1969 di jepang oleh pencetusnya yaitu Shigeo Shingo, pada mulanya dia berkonsultasi ke banyak perusahaan termasuk Toyota dia merenungkan mengenai ketidakmampuan mengeleminasi bottleneck pada car body moulding presses. Bottleneck ini disebabkan oleh lamanya changover time sementara ukuran lot produksi besar. Lot size yang ekonomis dikalkulasi dari perbandingan waktu produksi dan changeover time dimana waktu yang diperlukan untuk menyetop produksi dari sebuah produk dan memulai produksi adalah sama. Jika change over memerlukan waktu yang lama maka akan timbul prodution loses sehingga biaya produksi akan meningkat juga.

Metode SMED ini terdiri dari dua tahap, yakni :

\section{Tahap Pertama}

Membedakan set up internal dan set up eksternal. Operasi set up internal dilakukan saat mesin dalam keadaan tidak beroperasi sedangkan set up eksternal dilakukan saat mesin beroperasi.

a. Menggunakan Daftar Cek (Checklist)

b. Memeriksa Kinerja dan Fungsi Mesin

c. Memperbaiki Sistem Transportasi dan Part-part Lainnya

\section{Tahap Kedua}

Mengkonversikan set up internal menjadi set up eksternal. Dengan melakukan konversi set up internal menjadi set up eksternal akan mampu mereduksi waktu set up hingga 30\%-50\%. Tahap-tahap yang dilakukan dalam mengkonversikan set up internal menjadi set up eksternal ini antara lain:

a. Mempersiapkan Kondisi Operasional yang Baik

b. Melakukan Standarisasi Fungsi

\section{Tahap Ketiga}

Memperbaiki semua aspek dalam operasi set up. Meskipun demikian waktu reduksi dengan mengkonversikan setup internal menjadi set up eksernal, ada banyak faktor lain yang bisa mempengaruhi reduksi ini di sejumlah kasus set up. Oleh karena itu harus dilakukan upaya pembakuan untuk mengefisienkan prosedur-prosedur dasar dalam operasi set up inernal maupun eksternal. Jadi tahap ketiga ini merupakan analisis dari masing-masing operasi dasar sebelumnya.

\section{Identifikasi Masalah}

Identifikasi masalah dalam penelitian ini dilakukan dengan wawancara 
terhadap staff section Pressing dan juga berdasarkan data-data yang diberikan oleh pihak perusahaan. Dari informasi yang didapatkan, maka dapat diketahui bahwa mesin feeder membutuhkan waktu setup mesin yang paling lama dan dalam pengerjaannya operator terkadang tidak mematuhi standar operasional kerja yang sudah ditetapkan. Ini membuat kapasitas produksi mesin menurun karena banyaknya waktu yang terbuang untuk melakukan Setup.

\section{Studi Kepustakaan}

Studi Pustaka yang didapat berasal dari referensi yang berkaitan dengan reduksi waktu proses. Tanpa disadari, Studi Pustaka juga dapat memberikan ilmu lebih bagi penulis.

\section{Studi Lapangan}

Studi lapangan merupakan studi yang secara langsung dilaksanakan oleh penulis melalui berbagai cara, seperti pengamatan langung dan juga wawancara dengan staff PT.XXX yang terkait dengan proses setup mesin. Dari studi ini diharapkan penulis dapatmengidentifikasi masalah yang muncul dan menghambat proses setup mesin feeder.

\section{Pengumpulan Data}

\section{a. Metode Pengumpulan Data}

Metode pengumpulan data yang digunakan dalam penelitian ini adalah metode pengamatan langsung.

b. Instrumen Penelitian

Instrumen penelitan adalah jam henti (stop watch) yang digunakan dalam melakukan pengamatan langsung.

\section{c. Data yang Dibutuhkan}

Adapun data yang dibutuhkan dalam penelitian ini adalah data primer dan data sekunder.

- Data Primer

Data primer diperoleh secara langsung yang meliputi :

a. Data uraian kerja mesin (OPS) mesin feeder AIDA 1100.

b. Data waktu set up mesin feeder AIDA 1100 yang didapat dengan menggunakan jam henti (stop watch)
- Data Sekunder

Adapun data sekunder yang diperoleh berdasarkan dokumentasi perusahaan antara lain :

a. Data gambaran umum dan produk yang dihasilkan perusahaan.

b. Data spesifikasi mesin-mesin produksi dan uraian proses produksi

c. Data struktur organisasi perusahaan

d. Data Layout section Pressing PT. ISI

\section{ANALISIS DAN PEMBAHASAN Pengolahan Data}

Langkah-langkah pengolahan data menggunakan metode SMED yang dilakukan dalam penelitian ini antara lain :

1) Mengidentifikasi internal set up dan eksternal set up tiap prosedur yang dilakukan.

2) Menghitung waktu baku sebelum perbaikan set up

3) Mengkonversi internal set up menjadi eksternal set up sehingga diperoleh prosedur set up yang baru.

4) Menghitung waktu baku setelah perbaikan set up dilakukan (Wignjosoebroto, 1995).

5) Menghitung persentase reduksi waktu yang dihasilkan

6) Merubah Layout dan menghitung penghematan man power.

\section{Analisa Data}

Hasil dari pengolahan data dapat dianalisa untuk mengetahui masalah masalah apa saja yang timbul dan bagaimana cara mengatasinya serta mencoba untuk memberikan usulan perbaikan. Analisa dilakukan dengan identifikasi usulan - usulan perbaikan apa saja yang masih mungkin dilakukan.

\section{Tinjauan Sistem}

Pada kajian ini terlebih dahulu di hitung waktu baku operasi setup mesin, dengan mempertimbangkan rating factor seperti terlihat pada tabel 1 .

Maka waktu normal operasi set up yang dilakukan oleh operator set up pada mesin, yaitu :

$\mathrm{Wn}=\mathrm{Wt} \times(1+\mathrm{Rf})$

$$
=1332,445 \times(1+0,14)
$$


$=1332,445 \times 1,14$

$=1518,98$ detik

$=25,31$ menit

Tabel 1 Penentuan Rating Factor untuk Operator Set up

\begin{tabular}{|c|c|c|c|}
\hline$\overline{\text { No }}$ & Faktor & Kelas/Lambang & Nilai \\
\hline$\overline{1}$ & Keterampilan & Good Skill (C1) & $+0,06$ \\
\hline 2 & Usaha (effort) & Good Effort & $+0,05$ \\
\hline 3 & Kondisi & Good (C) & $+0,02$ \\
\hline 4 & $\begin{array}{l}\text { Konsistensi } \\
\text { (consistency) }\end{array}$ & Good (C) & $+0,01$ \\
\hline \multicolumn{3}{|c|}{$\overline{\text { Tota }}$} & 0,14 \\
\hline
\end{tabular}

Besarnya kelonggaran (allowance) operator set up pada mesin dapat dilihat pada tabel 2 berikut :

Tabel 2 Penentuan Allowance untuk Operator Set up

\begin{tabular}{|c|c|c|c|}
\hline No & Faktor & Kelas & Allowance(\% \\
\hline 1 & $\begin{array}{l}\text { Kebutuhan } \\
\text { pribadi } \\
\text { operator set } \\
\text { up }\end{array}$ & Pria & 1,0 \\
\hline 2 & $\begin{array}{l}\text { Tenaga } \\
\text { yang } \\
\text { dikeluarkan } \\
\text { (pria) }\end{array}$ & Sedang & 8,0 \\
\hline 3 & Sikap kerja & $\begin{array}{l}\text { Berdiri di atas } \\
\text { dua kaki }\end{array}$ & 2,0 \\
\hline 4 & $\begin{array}{l}\text { Gerakan } \\
\text { kerja }\end{array}$ & Normal & 0,0 \\
\hline 5 & $\begin{array}{l}\text { Kelelahan } \\
\text { mata }\end{array}$ & $\begin{array}{l}\text { Pandangan } \\
\text { yang } \\
\text { terputus- } \\
\text { putus }\end{array}$ & 3,0 \\
\hline 6 & $\begin{array}{l}\text { Keadaan } \\
\text { temperatur } \\
\text { tempat kerja }\end{array}$ & Normal & 2,5 \\
\hline 7 & $\begin{array}{l}\text { Keadaan } \\
\text { atmosfer }\end{array}$ & Cukup & 1,0 \\
\hline
\end{tabular}

Tabel 2 Penentuan Allowance untuk

\begin{tabular}{lll}
\multicolumn{3}{c}{ Operator Set up } \\
\hline 8 & $\begin{array}{l}\text { Keadaan } \\
\text { lingkungan } \\
\text { yang baik }\end{array}$ & Cukup bising \\
& 1,0 \\
\hline Total & 18,5
\end{tabular}

Maka waktu baku pengerjaan set up selama mesin berhenti / tidak beroperasi yaitu :

Ws $=$ Wn $\mathrm{x}(1+$ All $)$

$=1518,98 \times(1+0,185)$

$=1518,98 \times 1,185$

$=1800$ detik

$=30$ menit

Untuk mengetahui operasi setup pada system kajian maka diperlukan gambar layout kerja operator mesin feeder seperti terlihat pada gambar 1 .

Dan hasil pengamatan operasi setup diperlihatkan pada tabel 3 .

\section{Implementasi SMED}

Dalam melakukan implementasi konsep SMED, maka dari table 3 harus diubah model kegiatannya yaitu mengkonversikan Internal Set $U p$ dan Eksternal Set Up dan hasilnya ada pada table 4.

Maka selisih waktu baku aktual dengan ketetapan waktu baku dapat dihitung dengan :

Selisih $=1954,24 \mathrm{~s}-1352,48 \mathrm{~s}$

$=601,76 \mathrm{~s}$

Presentase $=(601,76 / 1954,24) \times 100 \%$

$$
=30,79 \%
$$
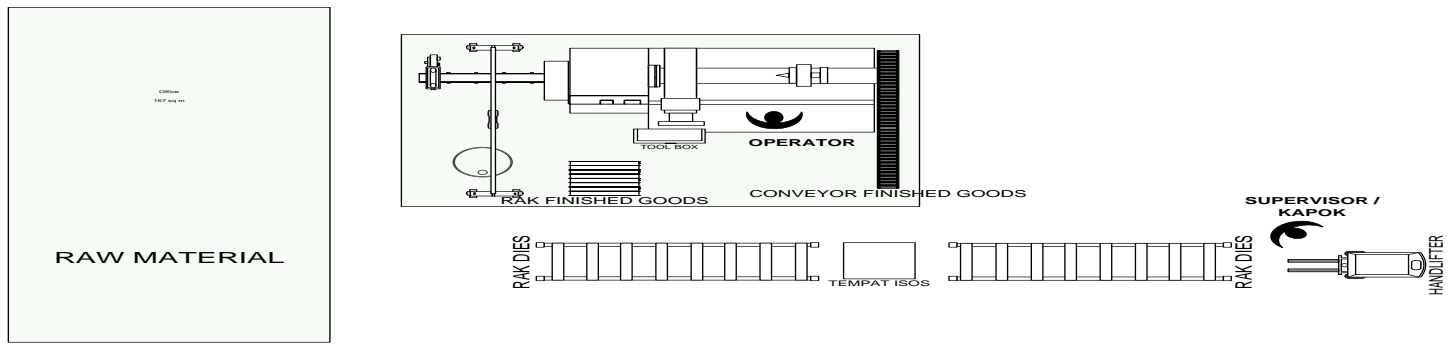

Gambar 1 Layout Kerja operator mesin feeder 
Tabel 3 Identifikasi Internal / Eksternal Setup

\begin{tabular}{|c|c|c|c|c|c|}
\hline No & Kegiatan & Tempat & Waktu(s) & $\begin{array}{l}\text { Internal } \\
\text { Setup }\end{array}$ & $\begin{array}{l}\text { Eksternal } \\
\text { Setup }\end{array}$ \\
\hline 1 & Mengambil raw material(coil) & Storage & 214,43 & $\checkmark$ & \\
\hline 2 & Memasang Coil ke rantai pengangkat coil & Mesin & 102,23 & $\checkmark$ & \\
\hline 3 & Melepas jembatan conveyor & Mesin & 12,03 & $\checkmark$ & \\
\hline 4 & Melepas Injector & Mesin & 20,76 & $\checkmark$ & \\
\hline 5 & Menutup Dies & Mesin & 21,43 & $\checkmark$ & \\
\hline 6 & Melepas baut Dies & Mesin & 63,57 & $\checkmark$ & \\
\hline 7 & $\begin{array}{l}\text { Mengambil dan menata Finished Goods dari } \\
\text { wadah }\end{array}$ & $\begin{array}{c}\text { Mesin } \\
\text { Tempat }\end{array}$ & 93,1 & $\checkmark$ & \\
\hline 8 & Mengantar Finished Goods & $\begin{array}{l}\text { Finished } \\
\text { Goods } \\
\text { Tempat }\end{array}$ & 85,91 & $\checkmark$ & \\
\hline 9 & Mengambil Handlifter & $\begin{array}{l}\text { Iempat } \\
\text { Handlifter }\end{array}$ & 208,23 & $\checkmark$ & \\
\hline 10 & Mengembalikan Dies ke rak dies & Rak Dies & 38,23 & $\checkmark$ & \\
\hline 11 & Mengambil Dies selanjutnya & Rak Dies & 155,55 & $\checkmark$ & \\
\hline 12 & Membersihkan sisa Scrap pada mesin & Mesin & 28,55 & $\checkmark$ & \\
\hline 13 & Memasang Dies & Mesin & 37,62 & $\checkmark$ & \\
\hline 14 & Mengembalikan Handlifter & $\begin{array}{l}\text { Tempat } \\
\text { Handlifter }\end{array}$ & 57,23 & $\checkmark$ & \\
\hline 15 & Mensetting Die Height & Mesin & 32,8 & $\checkmark$ & \\
\hline 16 & Mereset Mesin & Mesin & 29,38 & $\checkmark$ & \\
\hline 17 & Memasang baut Dies & Mesin & 102,08 & $\checkmark$ & \\
\hline 18 & Cek stroke mesin pada dies & Mesin & 28,05 & $\checkmark$ & \\
\hline 19 & Memasang jembatan conveyor & Mesin & 60,55 & $\checkmark$ & \\
\hline 20 & Melepas Coil Guard depan & Mesin & 55,33 & $\checkmark$ & \\
\hline 21 & Mensetting Coil Guard belakang & Mesin & 54,01 & $\checkmark$ & \\
\hline 22 & Membuka bungkus coil & Mesin & 74,21 & $\checkmark$ & \\
\hline 23 & Memasang Coil ke drum Uncoiler & Mesin & 48,14 & $\checkmark$ & \\
\hline 24 & Memasang kembali Coil Guard & Mesin & 45,23 & $\checkmark$ & \\
\hline 25 & Memotong ujung Coil & Mesin & 24,24 & $\checkmark$ & \\
\hline 26 & $\begin{array}{l}\text { Memutar drum uncoiler hingga ujung coil } \\
\text { dibawah Pinch Roller }\end{array}$ & Mesin & 46,22 & $\checkmark$ & \\
\hline 27 & $\begin{array}{l}\text { Mengatur work roll adjustment sesuai tebal } \\
\text { coil }\end{array}$ & Mesin & 13,38 & $\checkmark$ & \\
\hline 28 & Set parameter mesin & Mesin & 39,48 & $\checkmark$ & \\
\hline 29 & $\begin{array}{l}\text { Jalankan material hingga ujung coil masuk ke } \\
\text { dies }\end{array}$ & Mesin & 42,79 & $\checkmark$ & \\
\hline 30 & Atur set mesin & Mesin & 35,38 & $\checkmark$ & \\
\hline 31 & Nyalakan dan tes satu stroke ke coil & Mesin & 23,85 & $\checkmark$ & \\
\hline 32 & Memasang selang & Mesin & 17,73 & $\checkmark$ & \\
\hline 33 & Set conveyor sesuai ketentuan & Mesin & 28,85 & $\checkmark$ & \\
\hline 34 & Rubah ke continous dan jalankan & Mesin & 13,67 & $\checkmark$ & \\
\hline
\end{tabular}


Tabel 4 Konversi Internal dan Eksternal Setup

\begin{tabular}{|c|c|c|c|c|c|}
\hline No & Kegiatan & Tempat & Waktu(s) & $\begin{array}{l}\text { Internal } \\
\text { Setup }\end{array}$ & $\begin{array}{l}\text { Eksternal } \\
\text { Setup }\end{array}$ \\
\hline 1 & Mengambil raw material(coil) & Storage & 214,43 & & $\checkmark$ \\
\hline 2 & Memasang Coil ke rantai pengangkat coil & Mesin & 102,23 & & $\checkmark$ \\
\hline 3 & Melepas jembatan conveyor & Mesin & 12,03 & $\checkmark$ & \\
\hline 4 & Melepas Injector & Mesin & 20,76 & $\checkmark$ & \\
\hline 5 & Menutup Dies & Mesin & 21,43 & $\checkmark$ & \\
\hline 6 & $\begin{array}{l}\text { Melepas baut Dies } \\
\text { Mengambil dan menata Finished Goods dari }\end{array}$ & Mesin & 63,57 & $\checkmark$ & \\
\hline 7 & $\begin{array}{l}\text { Wengambil dan menata Finisned Goods dari } \\
\text { wadah }\end{array}$ & $\begin{array}{l}\text { Mesin } \\
\text { Tempat Finished }\end{array}$ & 93,1 & $\checkmark$ & $\checkmark$ \\
\hline 8 & Mengantar Finished Goods & $\begin{array}{l}\text { Goods } \\
\text { Tempat }\end{array}$ & 85,91 & $\checkmark$ & \\
\hline 9 & Mengambil Handlifter & Handlifter & 208,23 & & \\
\hline 10 & Mengembalikan Dies ke rak dies & Rak Dies & 38,23 & $\checkmark$ & \\
\hline 11 & Mengambil Dies selanjutnya & Rak Dies & 155,55 & $\checkmark$ & \\
\hline 12 & Membersihkan sisa Scrap pada mesin & Mesin & 28,55 & $\checkmark$ & \\
\hline 13 & Memasang Dies & $\begin{array}{l}\text { Mesin } \\
\text { Tempat }\end{array}$ & 37,62 & $\begin{array}{l}\checkmark \\
\checkmark\end{array}$ & \\
\hline 14 & Mengembalikan Handlifter & Handlifter & 57,23 & & \\
\hline 15 & Mensetting Die Height & Mesin & 32,8 & $\checkmark$ & \\
\hline 16 & Mereset Mesin & Mesin & 29,38 & $\checkmark$ & \\
\hline 17 & Memasang baut Dies & Mesin & 102,08 & $\checkmark$ & \\
\hline 18 & Cek stroke mesin pada dies & Mesin & 28,05 & $\checkmark$ & \\
\hline 19 & Memasang jembatan conveyor & Mesin & 60,55 & $\checkmark$ & \\
\hline 20 & Melepas Coil Guard depan & Mesin & 55,33 & $\checkmark$ & \\
\hline 21 & Mensetting Coil Guard belakang & Mesin & 54,01 & $\checkmark$ & \\
\hline 22 & Membuka bungkus coil & Mesin & 74,21 & & $\checkmark$ \\
\hline 23 & Memasang Coil ke drum Uncoiler & Mesin & 48,14 & $\checkmark$ & \\
\hline 24 & Memasang kembali Coil Guard & Mesin & 45,23 & $\checkmark$ & \\
\hline 25 & Memotong ujung Coil & Mesin & 24,24 & $\checkmark$ & \\
\hline 26 & $\begin{array}{l}\text { Memutar drum uncoiler hingga ujung coil } \\
\text { dibawah Pinch Roller } \\
\text { Mengatur work roll adjustment sesuai tebal } \\
\text { coil }\end{array}$ & Mesin & $\begin{array}{l}46,22 \\
13,38\end{array}$ & $\checkmark$ & \\
\hline 28 & $\begin{array}{l}\text { Set parameter mesin } \\
\text { Jalankan material hingga ujung coil masuk }\end{array}$ & Mesin & 39,48 & $\begin{array}{l}\checkmark \\
\checkmark\end{array}$ & \\
\hline 29 & ke dies & Mesin & 42,79 & & \\
\hline 30 & Atur set mesin & Mesin & 35,38 & $\checkmark$ & \\
\hline 31 & Nyalakan dan tes satu stroke ke coil & Mesin & 23,85 & $\checkmark$ & \\
\hline 32 & Memasang selang & Mesin & 17,73 & $\checkmark$ & \\
\hline 33 & Set conveyor sesuai ketentuan & Mesin & 28,85 & $\checkmark$ & \\
\hline 34 & Rubah ke continous dan jalankan & Mesin & 13,67 & $\checkmark$ & \\
\hline \multicolumn{3}{|c|}{ Total Waktu } & 1954,24 & 1352,48 & 601,76 \\
\hline
\end{tabular}

Ternyata hasil usulan perbaikan memilik selisih yang tidak beda jauh dengan waktu baku yang ditetapkan oleh perusahaan,ini disebabkan banyaknya kerja operator dalam setup mesin yang membuang waktu, serta peralatan yang digunakan oleh operator belum maksimal, ini dapat di reduksi lagi dengan memperbaiki aspek - aspek yang ada dalam operasi Setup. 


\section{Memperbaiki Semua Aspek dalam Operasi Set up}

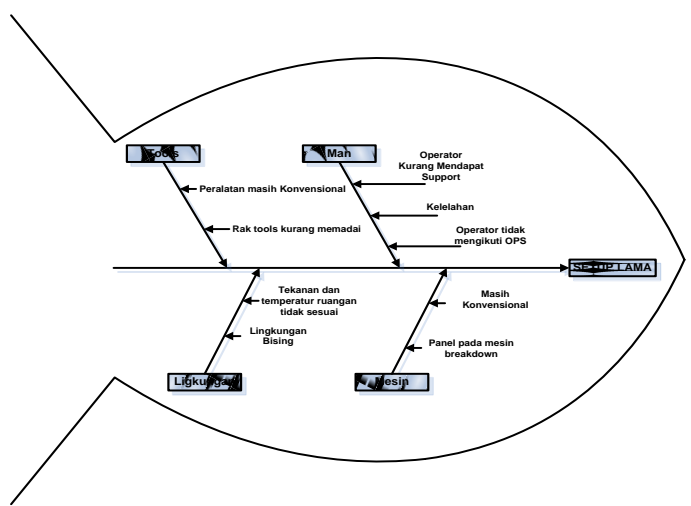

Gambar 2 Diagram fishbone

Dengan melihat diagram fishbone pada gambar 2 diatas maka terdapat beberapa faktor penyebab tingginya waktu set up mesin produksi mesin yaitu :

1. Tidak dibedakannya internal set up dan eksternal set up.

Berdasarkan pengamatan terlihat bahwa semua kegiatan set up dilakukan pada saat mesin berhenti, hal ini menandakan bahwa semua kegiatan dianggap sebagai internal set up.

2. Penyesuaian setting yang tidak tetap.

Dalam penyesuaian setting (adjustment) set up operator set up dilakukan secara berulang-ulang (trial and error adjustment) sehingga akan terjadi beberapa kali mesin dimatikan dan dihidupkan sewaktu melakukan uji coba ketepatan setting tersebut.

3. Peralatan yang belum maksimal

Alat bantu yang digunakan oleh operator seharusnya bisa lebih baik, karena alat bantu yang digunakan kurang dapat menghemat waktu setup proses mesin. Beberapa alat bahkan masih konvensional dan tidak praktis.

4. Kerjasama antar operator kurang

Dalam proses Setup dibutuhkan kerjasama antara supervisor yang mengambil handlifter dan juga Operator Forklift pengangkut material dengan operator sehingga proses tidak berlangsung lama.

Operasi Setup ini masih dapat direduksi lagi dengan membuat prosedur setup proses yang benar atau dengan mengunakan alat bantu, diantara lain adalah

1. Mengganti Dies lebih cepat (Gambar 3) dengan menggunakan alat bantu

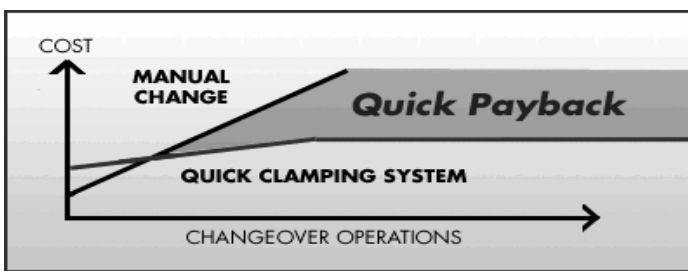

Gambar 3 Operasi changeover

2. Proses penggantian dies seharusnya dapat dilakukan lebih cepat, karena dengan mempercepat penggantian kita dapat meningkatkan :

- Otomasi

- Efisiensi

- Meningkatkan Produktifitas

- Pengoperasian yang lebih mudah Contoh alat pengganti Dies (gambar 4) yang dapat digunakan.

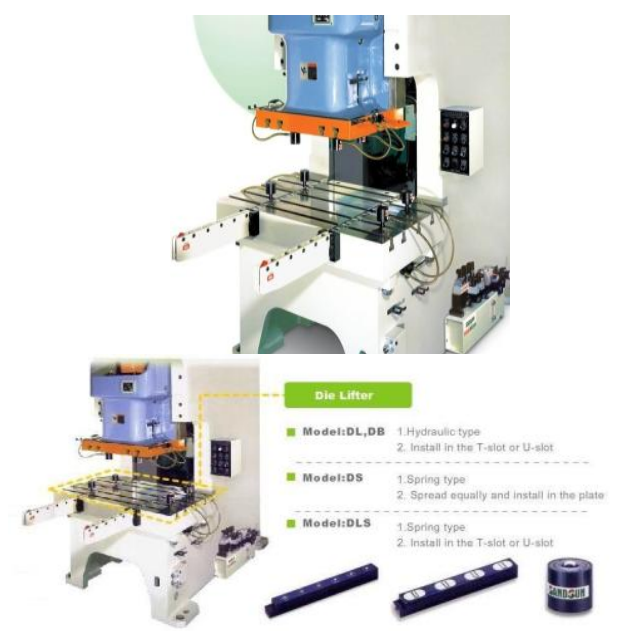

Gambar 4 Contoh alat pengganti Dies

Alat ini dibutuhkan untuk Quick Change System Dies untuk mesin Press, termasuk Air Pump Hydraulic Driven Unit, Die Clamp, Die Lifter, dan Die Arm. Ini dapat membantu untuk penggantian dies dalam waktu singkat. Alat ini menggantikan metode konvensional yang menggunakan sekrup untuk memperbaiki letak atau memasang cetakan / dies. Sehingga pemasangan dies menjadi lebih ringkas. 
Dengan menggunakan alat tersebut penggantian dies tidak lagi membutuhkan 2 operator sehingga dapat menghemat waktu dalam penggantiannya. Dalam hal ini diharapkan Kapok (Kepala Produksi) ataupun Supervisor yang membatu operator dalam penggantian dies beralih untuk kegiatan mengambil dies selanjutnya, sehingga waktu setup juga dapat dipersingkat.

3. Penggunaan Handlifter yang lebih Praktis

Handlifter (gambar 5) yang digunakan sekarang dirasa kurang praktis karena Handlifter hanya dapat membawa satu Dies sehingga operator melakukan pekerjaan berulang - ulang dalam penggantian dies. Dalam kondisi sekarang operator membuang waktunya untuk mengambil handlifter, mengembalikan dies ke rak, mengambil dies selanjutnya, dan juga mengembalikan handlifter lagi ke tempat parkir handlifter. Dengan handlifter yang dapat membawa 2 dies sekaligus ini dapat mempersingkat waktu hampir setengahnya, apalagi dengan penggunaan alat bantu penggantian dies seperti yang dijabarkan pada nomer 1, maka pengambilan handlifter dapat dilaksanakan oleh Kapok atau Supervisor, sehingga operator dapat menjalankan proses Setup yang lainnya.

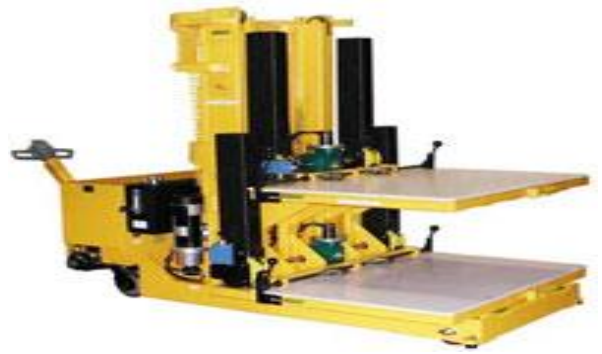

Gambar 5 Handlifter Dual station Green Valley - Titan 1614

4. Penggunaan Andon Light Visual Control

Sistem andon pada gambar 6 diatas merupakan aspek penting dari pengendalian visual berstandar di pabrik dan dalam pelaksanaan program manufaktur ramping yang sukses.

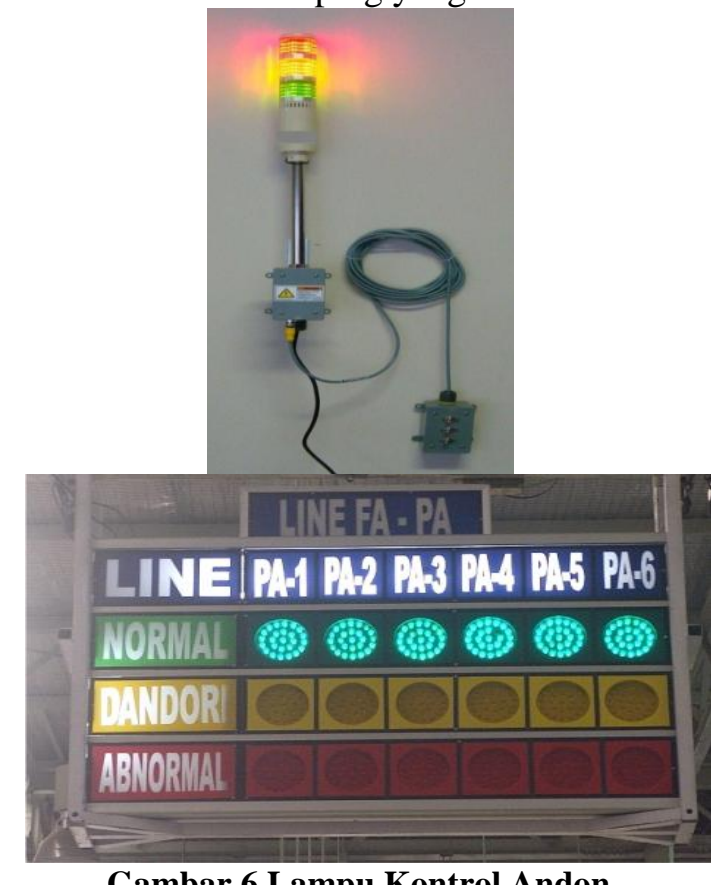

Gambar 6 Lampu Kontrol Andon

Lampu Andon akan meningkatkan waktu respon oleh sumber daya dukungan untuk operasional pabrik. Andons dapat digunakan untuk tujuan ganda - sinyal bantuan, masalah mesin, dan banyak lagi. Lampu Andon merupakan alternatif yang kuat karena biaya yang lebih rendah untuk tanda visual dalam alarm sebagai sinyal.

Penggunaan lampu Andon di sini dapat digunakan untuk peringatan bagi operator lain maupun kapok / supervisor bahwa operator sedang membutuhkan bantuan. Pemanfaatannya lebih kepada sinyal untuk Kapok/Supervisor bahwa akan terjadi pergantian dies, sehingga persiapan dapat dilakukan lebih dini. Lampu Andon disini juga dapat menghilangkan operator pada mesin feeder, karena mesin berjalan otomatis. Sehingga operator dari mesin Press lain dapat merangkap untuk melakukan setting mesin feeder. Operator hanya akan menju mesin feeder apabila lampu andon menyala, tanda bahwa mesin feeder akan melakukan setup mesin lagi. 
5. Penataan Rack Tools

Rack Tools yang tertata (gambar 7), bersih, dan menyediakan peralatan yang berkualitas baik sangat membantu operator dalam mempercepat proses setup mesin AIDA 1100. Dengan menggunakan Rack Tools ini diharapkan operator dapat dengan cepat mencari tools yang sedang dibutuhkan sehingga tidak membuang waktu saat proses mencari tools. Tools dengan kualitas yang baik dan selalu dijaga akan memudahkan operator dalam pengoperasiannya, ini juga penting dalam mereduksi waktu setup. Berikut merupakan contoh rack tools yang baik :
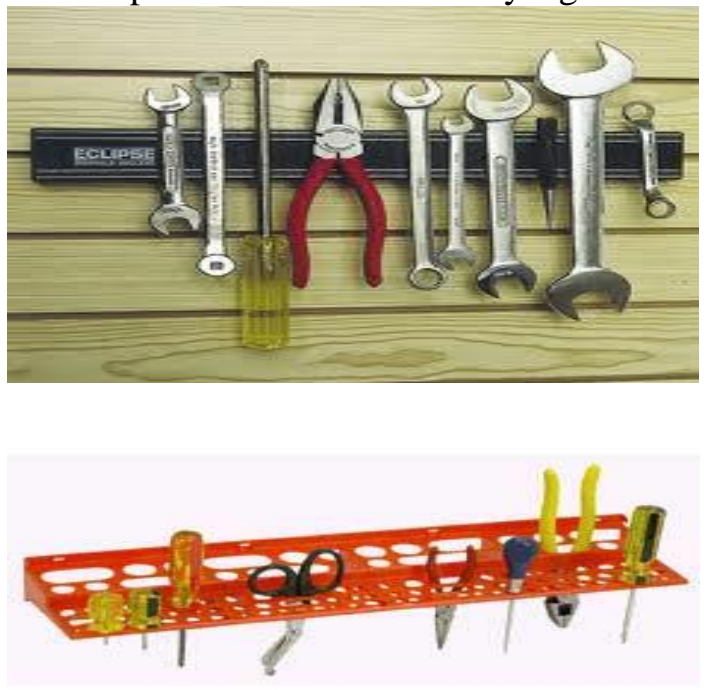

Gambar 7 Contoh Rack Tools yang baik

6. Training kepada operator maupun Kapok / Supervisor terhadap penggunaan alat baru dan pengenalan Lean Manufacturing.

Dengan menggunakan metode setup mesin baru dan juga alat bantu yang baru, maka butuh adaptasi dan pembakuan dari proses setup mesin tersebut. Oleh karena itu diharapkan semua operator terutama operator mesin AIDA 1100 T, dan juga Kapok beserta Supervisor untuk mengikuti training khusus proses Setting mesin dan juga penggunaan alat - alat bantu yang baru. Training ini dapat dilakukan secara visual langsung baik melalui video maupun praktek lapangan langsung. Sehingga kepatuhan terhadap standart kerja saat implementasi langsung dengan mudah dapat dipahami.

\section{Hasil Akhir Perbaikan ke-2}

Dengan melihat aspek - aspek operasi yang diusulkan maka terjadi perubahan waktu setup mesin yang lebih baik. Berikut ini tabel internal dan eksternal setup setelah dilakukan perbaikan ke -2 (Tabel 5).

Dari hasil tabel internal setup yang baru maka didapatkan waktu normal 883,3 $\mathrm{s}=14,72$ menit dan dengan menggunakan metode westinghouse maka dapat dihitung waktu bakunya sebagai berikut :

$$
\begin{aligned}
& \text { Ws }=\text { Wn } \times(1+\text { All }) \\
& =883,3 \times(1+0,135) \\
& =883,3 \times 1,135 \\
& =1002,54 \text { detik } \\
& =16,70 \text { menit } \\
& \text { Waktu Baku baru yang dicapai } \\
& \text { adalah 16,70 menit atau sama dengan } \\
& \text { 1002,54 detik. Dengan ini maka presentase }
\end{aligned}
$$

\section{Presentase Reduksi}

Maka presentase reduksi waktu setup mesin feeder mencapai 52,9 \%. Dan dengan melihat perubahan standar operasi kerja maka dapat dilakukan relayout pada mesin feeder sekaligus mengurangi man power. Operator pada mesin Press kecil Komatsu $80 \mathrm{~T}$ diharapkan dapat menggantikan posisi operator mesin feeder. Waktu yang disisihkan operator mesin Press kecil Komatsu $80 \mathrm{~T}$ ini dimasukkan kedalam allowance waktu baku operasi mesin Press kecil Komatsu $80 \mathrm{~T}$. 
Tabel 5 Konversi internal \& eksternal setup perbaikan ke-2

\begin{tabular}{|c|c|c|c|c|c|c|}
\hline $\begin{array}{l}\mathbf{N} \\
\mathbf{0}\end{array}$ & Kegiatan & Tempat & $\begin{array}{l}\text { Waktu } \\
\text { (s) }\end{array}$ & $\begin{array}{l}\text { Internal } \\
\text { Setup } \\
\end{array}$ & $\begin{array}{l}\text { Eksternal } \\
\text { Setup } \\
\end{array}$ & $\begin{array}{l}\begin{array}{l}\text { Keterangan } \\
\text { perubahan }\end{array} \\
\end{array}$ \\
\hline 1 & $\begin{array}{l}\text { Mengambil raw material(coil) } \\
\text { Memasang Coil ke rantai } \\
\text { pengangkat coil }\end{array}$ & Storage & 214,43 & & $\checkmark$ & $\begin{array}{l}\text { dilakukan saat } \\
\text { mesin beroperasi } \\
\text { dilakukan saat } \\
\text { mesin beroperasi }\end{array}$ \\
\hline 3 & Melepas jembatan conveyor & Mesin & 12,03 & $\checkmark$ & & \\
\hline 4 & Melepas Injector & Mesin & 20,76 & $\checkmark$ & & \\
\hline 5 & Menutup Dies & Mesin & 21,43 & $\checkmark$ & & $\begin{array}{l}\text { dipersingkat } \\
\text { dengan metode }\end{array}$ \\
\hline 6 & $\begin{array}{l}\text { Melepas baut Dies } \\
\text { Mengambil dan menata Finished }\end{array}$ & Mesin & 25 & $\checkmark$ & & $\begin{array}{l}\text { baru } \\
\text { dilakukan saat }\end{array}$ \\
\hline 7 & Goods dari wadah & $\begin{array}{l}\text { Mesin } \\
\text { Tempat } \\
\text { Finished }\end{array}$ & 93,1 & & $\checkmark$ & $\begin{array}{l}\text { mesin beroperasi } \\
\text { Bersamaan } \\
\text { dengan supervisor } \\
\text { mengambil }\end{array}$ \\
\hline 8 & Mengantar Finished Goods & $\begin{array}{l}\text { Goods } \\
\text { Tempat }\end{array}$ & 85,91 & & $\checkmark$ & $\begin{array}{l}\text { handlifter } \\
\text { menjadi tugas }\end{array}$ \\
\hline 9 & Mengambil Handlifter & Handlifter & 208,23 & & $\checkmark$ & $\begin{array}{l}\text { supervisor } \\
\text { membantu }\end{array}$ \\
\hline 10 & Mengambil Dies selanjutnya & Rak Dies & 30 & $\checkmark$ & & supervisor \\
\hline 11 & Menukar dan memasang dies & Mesin & 60 & $\checkmark$ & & \\
\hline 12 & $\begin{array}{l}\text { Membersihkan sisa Scrap pada } \\
\text { mesin }\end{array}$ & Mesin & 20 & $\checkmark$ & & \\
\hline 13 & Mengembalikan Dies ke rak dies & $\begin{array}{l}\text { Rak Dies } \\
\text { Tempat }\end{array}$ & 30 & $\checkmark$ & & $\begin{array}{l}\text { membantu } \\
\text { supervisor } \\
\text { menjadi tugas }\end{array}$ \\
\hline 14 & Mengembalikan Handlifter & Handlifter & 57,23 & & $\checkmark$ & supervisor \\
\hline 15 & Mensetting Die Height & Mesin & 32,8 & $\checkmark$ & & \\
\hline 16 & Mereset Mesin & Mesin & 29,38 & $\checkmark$ & & \\
\hline 17 & Memasang baut Dies & Mesin & 25 & $\checkmark$ & & $\begin{array}{l}\text { dipersingkat } \\
\text { dengan metode } \\
\text { baru }\end{array}$ \\
\hline 18 & Cek stroke mesin pada dies & Mesin & 28,05 & $\checkmark$ & & \\
\hline 19 & Memasang jembatan conveyor & Mesin & 60,55 & $\checkmark$ & & \\
\hline 20 & Melepas Coil Guard depan & Mesin & 55,33 & $\checkmark$ & & \\
\hline 21 & Mensetting Coil Guard belakang & Mesin & 54,01 & $\checkmark$ & & \\
\hline 22 & Membuka bungkus coil & Mesin & 74,21 & & $\checkmark$ & $\begin{array}{l}\text { dilakukan saat } \\
\text { mesin beroperasi }\end{array}$ \\
\hline 23 & Memasang Coil ke drum Uncoiler & Mesin & 48,14 & $\checkmark$ & & \\
\hline 24 & Memasang kembali Coil Guard & Mesin & 45,23 & $\checkmark$ & & \\
\hline 25 & Memotong ujung Coil & Mesin & 24,24 & $\checkmark$ & & \\
\hline 27 & $\begin{array}{l}\text { Memutar drum uncoiler hingga } \\
\text { ujung coil dibawah Pinch Roller } \\
\text { Mengatur work roll adjustment } \\
\text { sesuai tebal coil }\end{array}$ & Mesin & 46,22 & $\checkmark$ & & \\
\hline 28 & $\begin{array}{l}\text { Set parameter mesin } \\
\text { Jalankan material hingga ujung }\end{array}$ & Mesin & 39,48 & $\checkmark$ & & \\
\hline 29 & coil masuk ke dies & Mesin & 42,79 & $\checkmark$ & & \\
\hline 30 & Atur set mesin & Mesin & 35,38 & $\checkmark$ & & \\
\hline 31 & $\begin{array}{l}\text { Nyalakan dan tes satu stroke Ke } \\
\text { coil }\end{array}$ & Mesin & 23,85 & $\checkmark$ & & \\
\hline
\end{tabular}


Tabel 5 Konversi internal \& eksternal setup perbaikan ke-2 (Lanjutan)

\begin{tabular}{|c|c|c|c|c|c|c|}
\hline $\begin{array}{l}\mathbf{N} \\
\mathbf{0}\end{array}$ & Kegiatan & Tempat & $\begin{array}{l}\text { Waktu } \\
\text { (s) }\end{array}$ & $\begin{array}{l}\text { Internal } \\
\text { Setup }\end{array}$ & $\begin{array}{l}\text { Eksternal } \\
\text { Setup }\end{array}$ & $\begin{array}{l}\text { Keterangan } \\
\text { perubahan }\end{array}$ \\
\hline 32 & Memasang selang & Mesin & 17,73 & $\checkmark$ & & \\
\hline 33 & Set conveyor sesuai ketentuan & Mesin & 28,85 & $\checkmark$ & & \\
\hline 34 & Rubah ke continous dan jalankan & Mesin & 13,67 & $\checkmark$ & & \\
\hline \multicolumn{3}{|c|}{ Total Waktu } & 1718,64 & 883,3 & 835,34 & \\
\hline
\end{tabular}
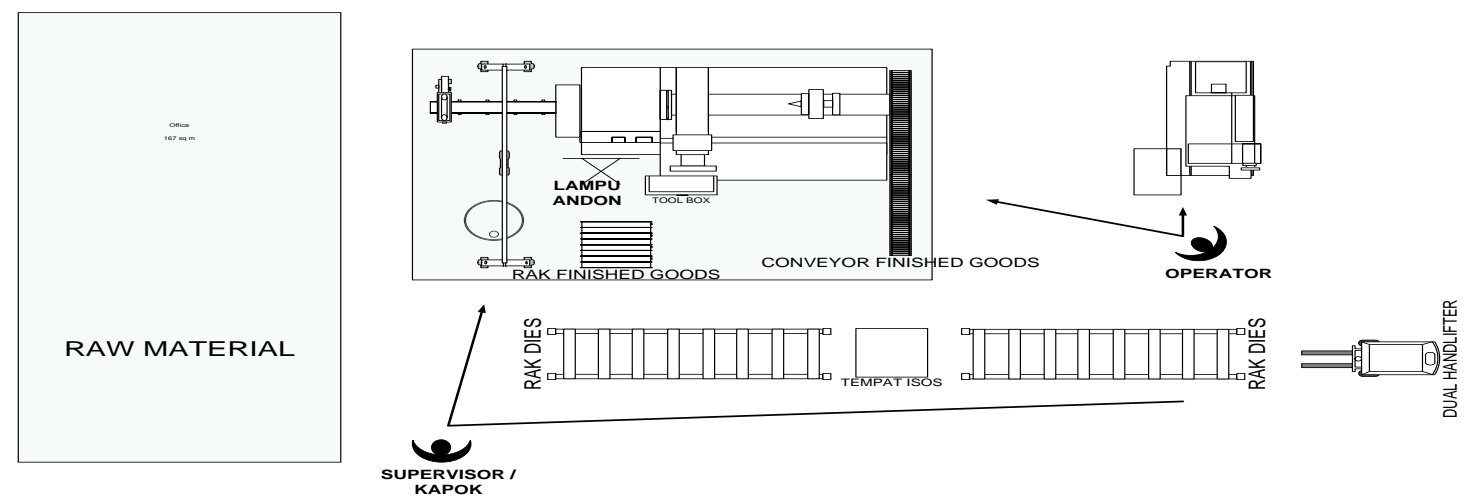

Gambar 8 Usulan Perbaikan Layout Kerja Mesin Feeder

Layout yang barupada gambar 8 telah disusun dengan pengoptimalan otomatisasi mesin feeder dan juga perlengkapan baru seperti lampu andon, sehingga dapat mengeliminasi operator mesin feeder. Cara kerja dari layout diatas adalah ketika mesin feeder akan memulai setup untuk proses selanjutnya, maka lampu andon akan otomatis menyala. Selanjutnya Operator dan Supervisor yang melihat lampu andon langsung mempersiapkan diri untuk proses setup mesin. Operator forklift yang melihat juga segera mengambil raw material selanjutnya.

Dengan mengurangi 1 man power maka perusahaan dapat menghemat sebesar Biaya 1 orang Per-bulan : Rp. 5.252.544,Biaya 1 orang Per-tahun : Rp. 63.030.528,Jadi Total Keuntungan saving 1 orang dalam 1 tahun :

Rp. 63.030.528,- $x 1$ org = Rp. 63.030.528,-.

\section{KESIMPULAN}

Sumber penyebab tingginya waktu set up mesin feeder AIDA 1100 T yaitu :

a. Tidak dibedakannya internal set up dan eksternal set up.

b. Penyesuaian setting yang tidak tetap.

c. Peralatan yang belum maksimal

d. Kerjasama antar operator kurang
Metode SMED merupakan metode yang cukup efisien dan efektif untuk mereduksi waktu set up. Hal ini dapat dilihat dari percepatan waktu baku baru hingga 1002,54 detik, sedangkan waktu baku lama adalah 1800 detik.

Dengan menggunakan metode SMED, maka diperoleh persentase penghematan waktu set up yaitu sebesar $\mathbf{5 2 , 9 \%}$.

Beberapa hal yang dapat dilakukan untuk mereduksi waktu set up, yaitu :

a. Mengganti sistem penggantian Dies konvensional menjadi otomatis.

b. Mengganti Handlifter dengan Dual Station Handlifter yang lebih efisien.

c. Menggunakan Andon Light Visual Control.

d. Menggunakan Rack Tools dan Tools yang kualitasnya lebih baik.

e. Training dan pengenalan Lean Manufacturing pada seluruh operator.

Relayout mesin feeder AIDA 1100 $\mathrm{T}$ mendukung diterapkannya standar operasi baru dan juga mengurangi man power yang dapat menghemat biaya hingga Biaya 1 orang Per-bulan : Rp. 5.252.544,Biaya 1 orang Per-tahun : Rp. 63.030.528,- 
Hasil perbaikan metode ini perlu diperhatikan oleh perusahaan sehingga dapat diterapkan pada pelaksanaan operasi set up sehingga perusahaan dapat menghasilkan produk yang lebih banyak dengan tipe yang berbeda dan juga dapat menghemat biaya produksi.

Perusahaan sebaiknya lebih sering melakukan penelitian dan kontrol secara terus menerus terhadap upaya-upaya untuk mereduksi waktu set up semua mesin produksi.

\section{DAFTAR PUSTAKA}

1. Barnes, Ralph M., (1980), Motion And Time Study Design And Measurement of Work. Seventh Edition. Canada : John Wiley \& Sons.
2. Nicholas, John. M., (1998), Competitive Manufacturing Management : Continuous Improvement, Lean Production, Customer-focussed Quality. International Edition. New York : McGraw-Hill Book Company.

3. Shingo, S., (1985), A Revolution in Manufacturing : The SMED System. Cambridge : Productivity Press.

4. Wignjosoebroto, S., (1995), Ergonomi, Studi Gerak dan Waktu. Edisi Pertama. Jakarta : PT. Guna Widya. 